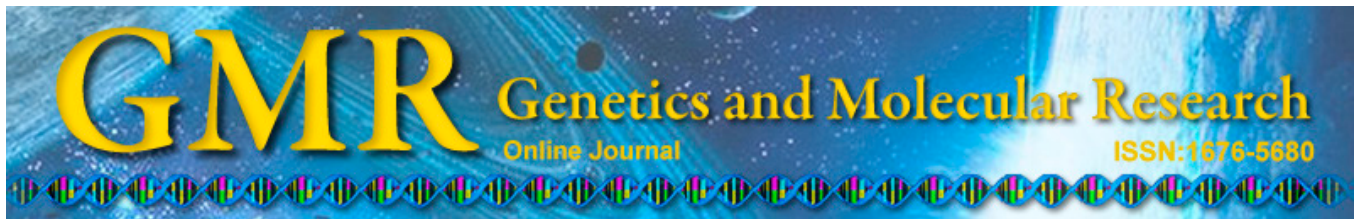

\title{
Molecular cloning and expression analysis of a novel BCCP subunit gene from Aleurites moluccana
}

\author{
W.Y. Xuan, Y. Zhang, Z.Q. Liu, D. Feng and M.Y. Luo \\ Guangxi University, Nanning, Guangxi Zhuang Autonomous Region, China \\ Corresponding author: W.Y. Xuan \\ E-mail: xuanweiyan_1@163.com
}

Genet. Mol. Res. 14 (3): 9922-9931 (2015)

Received March 6, 2015

Accepted June 9, 2015

Published August 19, 2015

DOI http://dx.doi.org/10.4238/2015.August.19.27

\begin{abstract}
Aleurites moluccana L. is grown as a roadside tree in southern China and the oil content of its seed is higher than other oil plants, such as Jatropha curcas and Camellia oleifera. A. moluccana is considered a promising energy plant because its seed oil could be used to produce biodiesel and bio-jet fuel. In addition, the bark, leaves, and kernels of $A$. moluccana have various medical and commercial uses. Here, a novel gene coding the biotin carboxyl carrier protein subunit (BCCP) was cloned from A. moluccana L. using the homology cloning method combined with rapid amplification of cDNA end (RACE) technology. The isolated full-length cDNA sequence (designated $A M$ accB) was $1188 \mathrm{bp}$, containing a 795-bp open reading frame coding for 265 amino acids. The deduced amino acid sequence of $A M-a c c B$ contained a biotinylated domain located between amino acids 190 and 263. A. moluccana BCCP shows high identity at the amino acid level to its homologues in other higher plants, such as Vernicia fordii, J. curcas, and Ricinus communis (86, 77, and 70\%, respectively), which all contain conserved domains for ACCase activity. The expression of the $A M-a c c B$ gene during the middle stage of development and maturation in $A$. moluccana seeds was higher than that in early and later stages.
\end{abstract}


The expression pattern of the $A M-a c c B$ gene is very similar to that of the oil accumulation rate.

Key words: Aleurites moluccana L.; BCCP subunit gene;

Molecular cloning; Sequence analysis; Expression analysis

\section{INTRODUCTION}

Aleurites moluccana $\mathrm{L}$. is a perennial, woody oil plant belonging to the family Euphorbiaceae and it is widely distributed in the tropics and subtropics worldwide. The oil content of its seeds is $66.22 \%$ (Liu et al., 2008), which is higher than other oil plants, such as peanut (Guo et al., 2012), rapeseed (Zhang et al., 2007), and Camellia oleifera (Wang et al., 2008). A. moluccana is a promising energy plant because of its high oil content, which could be used for biodiesel and bio-jet fuel production.

The oil content of plant seeds is affected by both genotype and environmental conditions, with the genotype playing a leading role. In the process of oil biosynthesis, there are a series of related pathways and catalysis of various enzymes. There are two distinct subcellular forms of acetyl-CoA carboxylase (ACCase) in plant cells; one is homomeric ACCase, mainly located in the cytosol and expressed constitutively, and the other heteromeric ACCase, is found in plastids and is expressed in developing seeds (Thelen et al., 2000; 2001; Sasaki and Nagano, 2004). The production of malonyl-CoA catalyzed by ACCase is the rate-limiting step in the process of fatty acid biosynthesis (Thelen et al., 2000; Fukuda et al., 2013). Previous studies have confirmed that heteromeric ACCase plays an important regulatory function during oil synthesis and accumulation in plant seeds (Thelen et al., 2000; Dong et al., 2004; $\mathrm{Hu}$ et al., 2009; Liu et al., 2009; Li et al., 2011). Homomeric ACCase is composed of a large multifunctional polypeptide (Sasaki and Nagano, 2004) and heteromeric ACCase is composed of a biotin carboxyl carrier protein (BCCP), biotin carboxylase (BC), and carboxyltransferase (CT), which consists of $\alpha$ - and $\beta$-subunits. Among the subunits of ACCase, BCCP subunit serves as the donor of activated carboxyl group and shuttles the tethered biotin between BC and CT domains, which is important for de novo fatty acid biosynthesis (Ke et al., 2000; Cronan, 2002; Sasaki and Nagano, 2004).

To date, the genes of many plant ACCase subunits have been cloned and analyzed, with the full-length cDNAs of ACCase subunit genes being in the range 1000 to $2947 \mathrm{bp}$ and showing 50 to $98.8 \%$ sequence identity with each other in the same gene of different plants (Tan et al., 2010; Gu et al., 2011). The synthesis and accumulation of oil in plant seeds is closely related to the expression level of ACCase genes during seed development (Chen et al., 2009; Rogalski and Carrer, 2011).

In many plants, such as Arabidopsis, Brassica napus, Vernicia fordii, Jatropha, soybean, and castor bean, the BCCP subunit gene of ACCase has been successfully cloned (Choi et al., 1995; Elborough et al., 1996; Reverdatto et al., 1999; Thelen et al., 2001; Gu et al., 2011; Cui et al., 2012). The expression patterns of the BCCP subunit gene vary greatly in different tissues and organs of plants. Arabidopsis expresses two paralogs of the BCCP subunit, where $\mathrm{BCCP} 1$ is coded by $B C C P 1$ and $\mathrm{BCCP} 2$ is coded by $B C C P 2$. The $B C C P 1$ transcript is expressed constitutively, while $B C C P 2$ is predominant in flowers and siliques and its overall abundance is approximately 4-fold lower than that of $B C C P 1$ (Thelen et al., 2000). The development of the endosperm and embryo is disrupted when $B C C P 1$ is knocked-out during Arabidopsis seed development, and fatty acid accumulation decreases and normal vegetative 
plant growth is severely affected when BCCP1 accumulation is reduced at the protein level ( $\mathrm{Li}$ et al., 2011). These results indicate that BCCP genes are involved in de novo lipid synthesis storage and accumulation (Elborough et al., 1996; Thelen et al., 2000; Gu et al., 2011). The lipid content of $A$. moluccana seeds is higher than that of many other plants, but little is known about the sequence structure of the BCCP subunit gene and its expression profile during seed development and oil accumulation in A. moluccana.

In this study, in order to explore the role of the BCCP subunit gene during seed development and oil accumulation in A. moluccana, the full-length cDNA sequence for the BCCP subunit was obtained successfully by employing homology cloning and the rapid amplification of cDNA end (RACE) technique. The expression profile of the gene and the oil content of the seeds were determined using quantitative real-time PCR (qRT-PCR) and Soxhlet, respectively. The results provide a basis for further research about nucleotide polymorphisms of the BCCP gene and molecular markers linked to the oil content of A. moluccana seeds.

\section{MATERIAL AND METHODS}

\section{Plant material}

Young leaves and seeds at various stages of development were collected from A. moluccana L. plants distributed in Guangxi University and stored at $-80^{\circ} \mathrm{C}$ until required.

\section{Total RNA extraction and cDNA synthesis}

Total RNA was extracted from young leaves and cDNA was synthesized using the RevertAid $^{\mathrm{TM}}$ First Strand cDNA Synthesis kit (Fermentas, Lithuania) with $5 \mu \mathrm{g}$ of RNA as a template, and following the manufacturer protocol.

\section{Degenerate primer design}

A pair of degenerate primers was designed using the online software CODEHOP (http://blocks.fhcrc.org/blocks/codehop.html) according to the conserved amino acid sequences of BCCP in related species. The primer sequences are described in Table 1.

\section{cDNA of the gene coding for the BCCP subunit cloned from A. moluccana $L$.}

The middle fragment of cDNA coding for the BCCP subunit was amplified by PCR using the degenerate primer pair described in Table 1. PCR products were cloned into a pUCm$\mathrm{T}$ vector (Sangon, Shanghai, China), and transferred into competent cells of Escherichia coli strain DH51 $\alpha$. The positive clones were screened out using blue-white selection, confirmed by PCR, and sequenced. The sequence was submitted to GenBank to identify similar genes through Blastx. To obtain the full-length cDNA sequence, a set of gene specific primers were designed according to the sequence of the middle fragment of cDNA for 5'- and 3'-RACE. These primers are shown in Table 1. The amplified sequences were cloned, sequenced, and assembled. Synthesis of all primers and sequencing were conducted by the Sangon. 


\section{Objective gene sequence analysis}

The location of the open reading frame (ORF) and DNA translation were predicted by using the online software ExPASy (http://web.expasy.org/translate/) and DNAMAN (Lynnon Biosoft, USA). Amino acid sequences of homologs from different plants were obtained from GenBank (http://www.ncbi.nlm.nih.gov/) and aligned using Biology Workbench 3.2 (http:// workbench.sdsc.edu/AlignmentTools). The software ExPASy (www.expasy.org) was used to analyze the theoretical isoelectric point (pI) and molecular weight of the predicted protein. The online software ProtScale (http://web.expasy.org/ProtScale/) and Predict Protein (http:// www.PredictProtein.org/) were used to analyze the hydropathicity and secondary structure composition of the predicted protein.

\section{Real-time RT-PCR analysis of gene expression}

Total RNA was isolated from the A. moluccana endosperm using RNAprep Pure Plant kits (TIANGEN Biotechnology Company, Beijing, China) according to the manufacturer protocol. First strand cDNA was synthesized using the RevertAid-TM First Strand cDNA synthesis kit (Fermentas) according to the manufacturer protocol. qRT-PCR was performed to examine expression of the BCCP subunit gene. The 18SrRNA gene was used as an internal control in A. moluccana. The specific primers for the internal control gene and the target gene used for qRT-PCR are shown in Table 1. The amplified fragment lengths of the control and target gene were 110 bp and 217 bp, respectively. Finally, cDNA was amplified using real-time PCR. All amplifications were performed using SYBR Premix ExTaq II (TaKaRa Biotechnology Company, Dalian, China). SYBR Green II assay reactions were performed in a $10 \mu \mathrm{L}$ volume and each reaction contained $5 \mu \mathrm{L}$ SYBR Premix ExTaq II, $400 \mathrm{nM}$ concentration of each primer, and cDNA. PCRs were performed with four biological replicates. Gene expression levels were evaluated using the delta/delta calculation method (Livak and Schmittgen, 2001). The data were then processed using the base 10 logarithm and Excel mapping.

\section{Seed oil content by Soxhlet analysis}

Oil content was quantified using Soxhlet analysis. A. moluccana seed samples were harvested at various stages of seed development and shelled and dried at $80^{\circ} \mathrm{C}$ for use to determine the oil content. Seed oil content was measured, and the mass of each measurement was converted to a percentage of the total weight of each sample. All samples were measured in triplicate ( 3 seeds for each replication) and the results averaged.

\section{RESULTS}

\section{Full length cDNA cloning of the BCCP subunit gene}

A middle fragment of the BCCP subunit gene (approximately 500 bp in length; Figure $1 \mathrm{~A}$ ) and its 5'-cDNA end (approximately $400 \mathrm{bp}$; Figure 1B) and a 3'-cDNA end (approximately $450 \mathrm{bp}$; Figure 1C) were amplified using RT-PCR with total RNA isolated from young leaves as a template and the degenerate, 5'-RACE, and 3'-RACE primers, respectively (Table 1). Sequencing results showed that the lengths of these fragments are 456, 473, and $494 \mathrm{bp}$, 
respectively. A full-length cDNA sequence of 1188 bp was obtained by assembling the fragments and was termed $A M$-accB. $A M$-accB contained a 795-bp ORF coding for 265 amino acids, a 5'-UTR of $202 \mathrm{bp}$, and a 3'-UTR of $191 \mathrm{bp}$.

Table 1. Primers* used for PCR.
\begin{tabular}{ll}
\hline Name & Sequence \\
\hline Degenerate primers P1 & 5'-TACTAAGATGCAAGCTCAAYTNAAYGARGT-3' \\
Degenerate primers P2 & 5'-CTATAAAAAGTTCCAGCCATNGGRCAYTT-3' \\
5' RACE GSP1 & 5'-TTTGCTCCTCCAAGTTCCAC-3' \\
5' RACE GSP2 & 5'-CAAGTGTCAGACCTTGTCAAGC-3' \\
5' RACE GSP3 & 5'-TTCTGTCCCTGTGCTAGACAAC-3' \\
3' RACE GSP1 & 5'-GTCAACTAAACGGCATTCCC-3' \\
3' RACE GSP2 & 5'-CTTATTTTAGTGTGTGCTTCCG-3' \\
18srRNA primers P1 & 5'-TGTTGCTTTTAGGACTCCGCCGG-3' \\
18srRNA primers P2 & 5'-GTGGTGCCCTTCCGTCAATTCCT-3' \\
Q-RT-PCR P1 & 5'-TCCAGAGTTCCATCATCCGAGGT-3' \\
Q-RT-PCR P2 & 5'-GCGCTGCAATGACAGGAGGT-3' \\
\hline *Y $=\mathrm{C} / \mathrm{T}, \mathrm{N}=\mathrm{A} / \mathrm{C} / \mathrm{G} / \mathrm{T}$. &
\end{tabular}

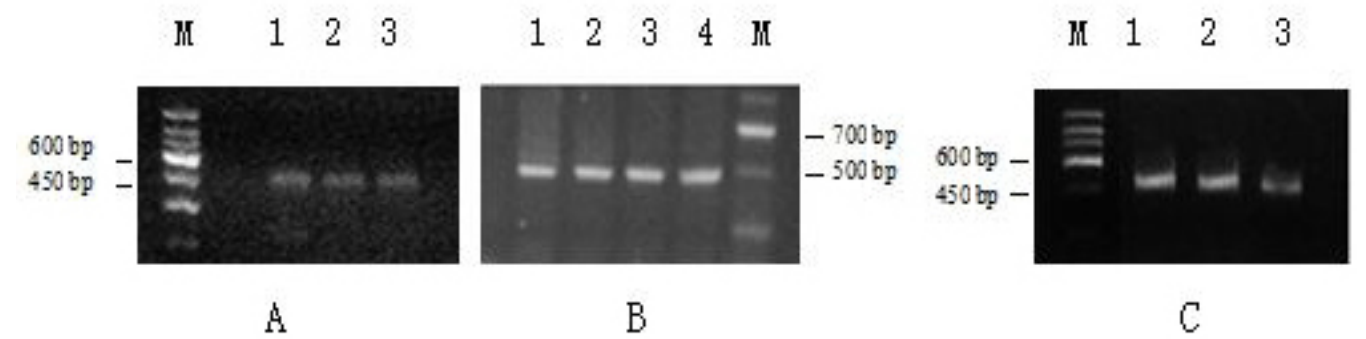

Figure 1. PCR amplification of the BCCP subunit in Aleurites moluccana A. Lanes 1 to 3: products of the middle fragment of the BCCP subunit sequence; B. lanes 1 to 4: 5'-cDNA products; C. lanes 1 to 3: 3'-cDNA products; lane $M$ : DNA marker.

\section{Sequence analysis of the BCCP subunit gene}

Homology analysis by Blastx revealed that $A M$-accB codes for the BCCP subunit of $A$. moluccana and shares high identity with sequences from $V$. fordii, J. curcas, and R. communis, (86, 77, and 70\%, respectively), based on amino acid sequence comparison. The BCCP subunit in A. moluccana (AM-BCCP) is a chloroplast located protein and its deduced amino acid sequence contains a biotinylated domain EAMKLMN located at the C-terminus between amino acids 190 and 263 (Figure 2). It has a molecular weight and theoretical isoelectric point of 28.2 $\mathrm{kDa}$ and 7.61, respectively. The predicted hydropathicity of AM-BCCP showed a minimum of -2.667 and a maximum of 1.844 . When the window size (using linear weight variation model) was 11, it had two peaks that scored $>1.5$ and 13 peaks that scored $<0$ (Figure 3 ). The results indicate that AM-BCCP has water-soluble properties. Analysis using the online software Predict Protein indicated that AM-BCCP secondary structure is composed of $12.08 \%$ helix, $17.74 \%$ sheet, and $70.19 \%$ loops, with one helix, seven sheets, and nineteen loops with a confidence value $>5$, and it has no potential transmembrane domain. Analysis using the online software SignalP (4.1 Server) showed that the AM-BCCP protein has no signal peptides. 


\begin{tabular}{|c|c|}
\hline $\mathrm{AM}-\mathrm{BCCP}$ & MASISWPCPNTASWARFGS - NAIPKLTISFTPRASSLLGFQWSNRKRS \\
\hline Vernicia fordii & MASISWPCPKTALVARFGSNATNPLPKSTISFPPRASSLLGFQWSNRKQS \\
\hline Jatropha curcas & MASISWPCPKTIL WARIGSNENPLPNSTVSFPPLTSNLLGFQWCNWK \\
\hline icinus comm & MASTSWPCPKTSFIARIGSNASNSLPKHTISFPSR- \\
\hline & $* .: *: *: *)$ \\
\hline
\end{tabular}

\begin{tabular}{|c|c|}
\hline $\mathrm{AM}-\mathrm{BCCP}$ & PVTKMQAQLNEVLAEKSSNSVPVLDNNSRVPSSEVKDEPAESNTPDASAI \\
\hline Vernicia fordii & PVTKWQAQLNEVLAEKSSNSWPVLDNNSKWPSSEQKDEPAENNIPDASAI \\
\hline Jatropha curcas & RVTKMQAKLNEVLLEKSSNSWPVLETNSNVPTPDEKDESTESNILDASQI \\
\hline Ricinus comunuis & AVTKWKAQLNEVIVKGSSNSWPMLDTNSKLAPSEVKDEAWWWWPDASAI \\
\hline
\end{tabular}

\begin{tabular}{|c|c|}
\hline $\mathrm{AM}-\mathrm{BCCP}$ & SAFFTQVSDL VKL VDSRDITELQLKQLGCEL IIRKKEALQQPLP-PVI \\
\hline Vernicia fordii & SAFMTQVSDL VKL VDSRDITELQLKQLGCEL I IRKKEALQQPPP-PVIA \\
\hline atropha curcas & SAFMTQVSDL VKL VDSRDITELQLKQLGCQLIIRKKEALQQPPPAAPV \\
\hline \multirow[t]{3}{*}{ Ricinus communis } & TEFMTQVSDL VKL VDSRDITELQLKQLDCEIIIRKKEALQ-PPPABQVI \\
\hline & : $* * * * * * * * * * * * * * * * * * * * * * * * * * * * . *:: * * * * * * * * * * * *$ \\
\hline & \\
\hline M-BCCP & AQPSYQHALLPSPPPAAPAFAPPSSTSPP-APALPSPAKTNTSRTP-LK \\
\hline Vernicia fordii & AQPSYQHAMLPSPPLAAPASAPPSSTPPPPAPALPSPAKSSTSSHPQLK \\
\hline Jatropha curcas & MPPSYQHTMLPSPPPAAPASAPPSS-PPLALALPPPAKTSSSSHPPLK \\
\hline \multirow[t]{2}{*}{ Ricinus communis } & 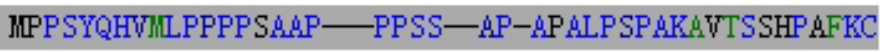 \\
\hline & $* * * * . * * * * * . * * *:: * * ; * * *$ \\
\hline
\end{tabular}

\begin{tabular}{|c|c|}
\hline $\mathrm{AM}-\mathrm{BCCP}$ & PMAGTFYRLPAPGEPPFWKWGDKQKGQWCIIEAMKLMEIEADQSGTI \\
\hline Vernicia fordii & PMAGTFYRCPAPGEPPFWKWRDKWQKGQWCIIEAMKLMLNE IEADQSGTI \\
\hline Jatropha curcas & PMAGTFYRNPAPGEPPFWKWGDWQKGQWCIIEAMKLMREIEADQAGTI \\
\hline \multirow[t]{3}{*}{ Ricinus communis } & PMAGTFYRCPAPGEPPFWKWGDKWQGQWCIIEAMKLMEIEADQSGTI \\
\hline & 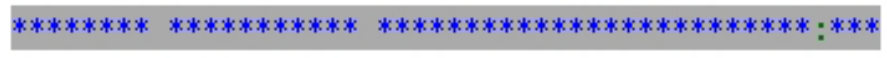 \\
\hline & 263 \\
\hline $\mathrm{AM}-\mathrm{BCCP}$ & AEILVEDGKPVSWDMPLFVISP \\
\hline Vernicia fordii & AEILVEDGKPVSVDLPLFVIAP \\
\hline Jatropha curcas & AEILVEDGKPVSWDMPLFWIAP \\
\hline \multirow[t]{2}{*}{ Ricinus communis } & TEVLAEDGKPVSWDTPLFWIVP \\
\hline & $: *: * . * * * * * * * * * * * * * * * * *$ \\
\hline
\end{tabular}

Figure 2. Amino acid homology comparison of the BCCP subunit in Aleurites moluccana and other higher plant species. *Fully conserved residue. 


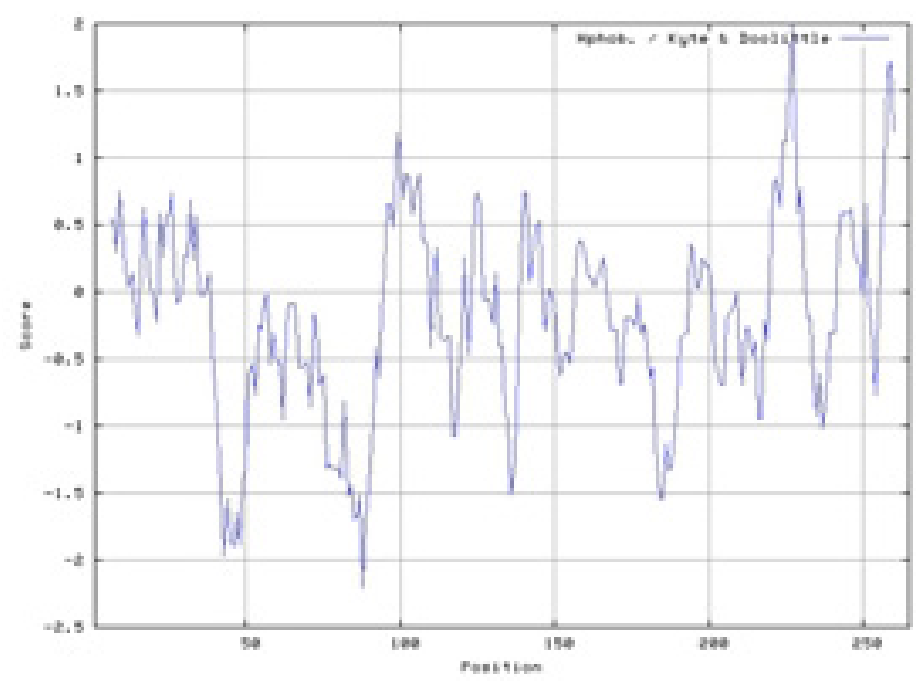

Figure 3. Hydropathicity of the BCCP subunit in Aleurites moluccana.

\section{Expression analysis of $A M-a c c B$ and changes in oil content during seed development}

The development period of $A$. moluccana seeds can be as long as 6 months in southern China. During the initial development stage, no endosperm is formed in the seeds of A. moluccana in March and April. Thus, we determined the lipid content of seeds from May onwards. The results show that the lipid content of seeds gradually increases during the process of development and maturation. Both the oil content and its accumulation rate were low in the early stage of development, and the accumulation rate of oil reached its highest level during the middle stage of development (June to August), with the oil content in dry kernels reaching $67.54 \%$ during the maturation stage (Figure 4). The expression pattern of the $A M-a c c B$ gene during $A$. moluccana endosperm development was very similar to that of the oil accumulation rate. The highest expression level of $A M-a c c B$ was observed during the middle stage of development (July) and expression during the maturation stage was higher than that during the early stage of development (Figure 5).

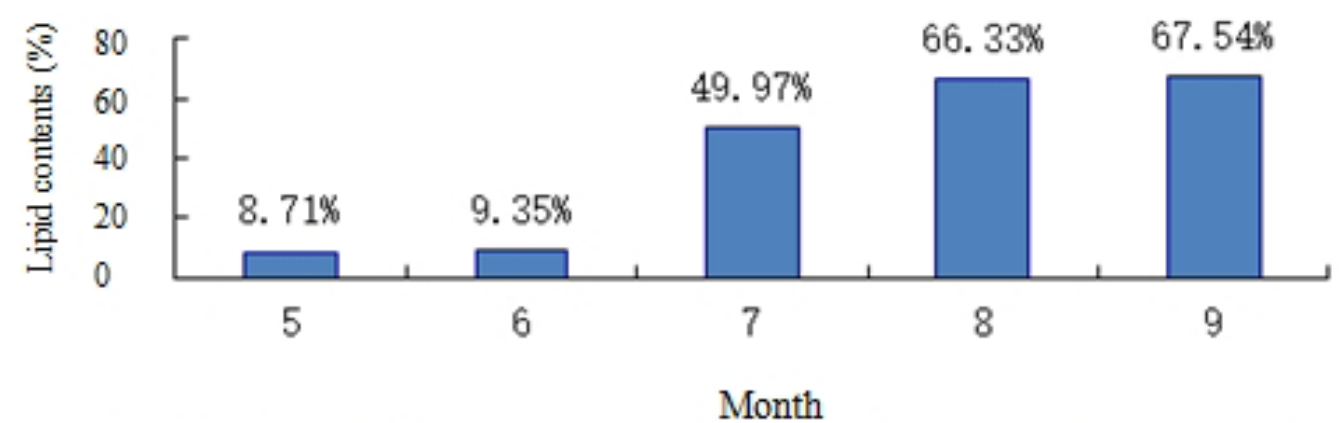

Figure 4. Variation in the lipid content of kernels at different stages during the development of Aleurites moluccana seeds. 


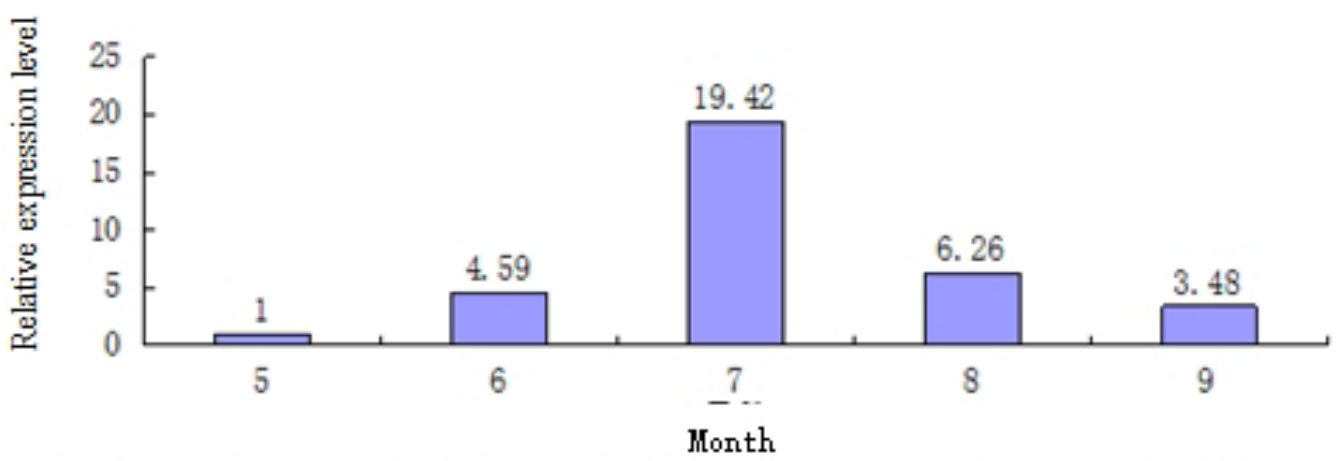

Figure 5. Expression of the AM-accB gene at different stages during the development of the endosperm in Aleurites moluccana.

\section{DISCUSSION}

The BCCP subunit is one of four subunits of ACCase. In many plants, the cDNA sequence length of the BCCP subunit gene ranges from $1013 \mathrm{bp}$ to $1480 \mathrm{bp}$, the deduced amino acid sequences are 258 to 286 amino acids in length, and the amino acid sequences have high identity between plants, ranging from 70 to $86 \%$ (Gu et al., 2011; Cui et al., 2012; Gong et al., 2013). Previous research has shown that the expression patterns of the BCCP subunit gene are very similar to that of the changes in oil accumulation during seed development (Cui et al., 2012), but to date there has been no report on the structural characteristics of the BCCP subunit gene and its expression patterns in A. moluccana. Therefore, the results of this study will be useful for further exploring the sequence polymorphisms of the BCCP subunit gene and developing molecular markers related to seed oil content in A. moluccana.

Although there are a number of methods for cloning the full-length coding sequence of plant genes, such as shotgun, in silico cloning, and chromosome walking, the homology cloning strategy combined with the RACE technique adopted in our study is one of the most simple, effective, and low cost.

The expression profile of the BCCP subunit gene in A. moluccana during the process of seed development and maturation is similar to that of its homologues in other woody plants, such as J. curcas, V. fordii, and C. oleifera (Gu et al., 2011; Cui et al., 2012; Zhou, 2013). Fatty acids are first synthesized and then changed into oil during the lipid synthesis process of plant seed development. During plant seed development, the expression peak of the ACCase subunit genes (accA, accB, accC, accD) appears in the fastest period of oil accumulation. In addition to accC, the transcriptional level of the other three genes was approximately 6 to 12 -fold higher than that in the early stage of seed development (Chen et al., 2009; Rogalski and Carrer, 2011). The highest expression of genes involved in fatty acid synthesis appeared approximately one month earlier than the fastest period of oil content increase in C. oleifera (Zhou, 2013). These results suggest that the BCCP subunit gene may play an important role in the fatty acid synthesis process. Further research into the relationship between gene expression and single nucleotide polymorphisms (SNPs) in the BCCP subunit gene and the content change of fatty acid during $A$. moluccana seed development is required. 


\section{Conflicts of interest}

The authors declare no conflict of interest.

\section{ACKNOWLEDGMENTS}

Research supported by the Key Project (\#0992021-3) of the Guangxi Science \& Technology Department and the Project (\#200809MS152) of the Guangxi Education Department.

\section{REFERENCES}

Chen M, Mooney BP, Hajduch M, Joshi T, et al. (2009). System analysis of an Arabidopsis mutant altered in de novo fatty acid synthesis reveals diverse changes in seed composition and metabolism. Plant Physiol. 150: 27-41.

Choi JK, Yu F, Wurtele ES and Nikolau BJ (1995). Molecular cloning and characterization of the cDNA coding for the biotin-containing subunit of the chloroplastic acetyl-coenzyme A carboxylase. Plant Physiol. 109: 619-625.

Cronan JE Jr (2002). Interchangeable enzyme modules. Functional replacement of the essential linker of the biotinylated subunit of acetyl-CoA carboxylase with a linker from the lipoylated subunit of pyruvate dehydrogenase. J. Biol. Chem. 277: 22520-22527.

Cui QQ, Han XJ, Chen YC, Zhan ZY, et al. (2012). Isolation and expression characteristics of biotin carboxyl carrier protein coding gene (VfBCCP) from Vernicia fordii. Sci. Sil. Sin. 48: 155-160.

Dong J, Keller WA, Yan W and Georges F (2004). Gene expression at early stages of Brassica napus seed development as revealed by transcript profiling of seed-abundant cDNAs. Planta. 218: 483-491.

Elborough KM, Winz R, Deka RK, Markham JE, et al. (1996). Biotin carboxyl carrier protein and carboxyltransferase subunits of the multi-subunit form of acetyl-CoA carboxylase from Brassica napus: cloning and analysis of expression during oilseed rape embryogenesis. Biochem. J. 315: 103-112.

Fukuda N, Ikawa Y, Aoyagi T and Kozaki A (2013). Expression of the genes coding for plastidic acetyl-CoA carboxylase subunits is regulated by a location-sensitive transcription factor binding site. Plant Mol. Biol. 82: 473-483.

Gong Y, Peng SD, Chen SW, Wang XJ, et al. (2013). Cloning and sequence analysis of acetyl-CoA carboxylase BCCP subunit from Yunan Xiao rapeseed (Brassica campestris). Mol. Plant Breeding. 11: 345-350.

Guo SY, Chen JH, Wang JX, Xiao Y, et al. (2012). Effects of seed size on yield and quality of peanuts. Fuj. J. Agricul. Sci. 27: 700-706.

Gu K, Chiam H, Tian D and Yin Z (2011). Molecular cloning and expression of heteromeric ACCase subunit genes from Jatropha curcas. Plant Sci. 180: 642-649.

$\mathrm{Hu}$ Y, Wu G, Cao Y, Wu Y, et al. (2009). Breeding response of transcript profiling in developing seeds of Brassica napus. BMC Mol. Biol. 10: 49.

Ke JS, Wen TN, Nikolau BJ and Wurtele ES (2000). Coordinate regulation of the nuclear and plastidic genes coding for the subunits of the heteromeric acetyl-Coenzyme A carboxylase. Plant Physiol. 122: 1057-1072.

Li X, Ilarslan H, Brachova L, Qian HR, et al. (2011). Reverse-genetic analysis of the two biotin-containing subunit genes of the heteromeric acetyl-coenzyme A carboxylase in Arabidopsis indicates a unidirectional functional redundancy. Plant Physiol. 155: 293-314.

Liu CS, Huang FH, Li CY, Wand MX, et al. (2008). Primary study on oil wood (Aleurites moluccana). Chin. J. Oil Crop Sci. 30: 106-107.

Liu Z, Yang X, Fu Y, Zhang Y, et al. (2009). Proteomic analysis of early germs with high-oil and normal inbred lines in maize. Mol. Biol. Rep. 36: 813-821.

Livak KJ and Schmittgen TD (2001). Analysis of relative gene expression data using real-time quantitative PCR and the 2[-Delta Delta C(T)] method. Methods 25: 402-408.

Reverdatto S, Beilinson V and Nielsen NC (1999). A multisubunit acetyl coenzyme A carboxylase from soybean. Plant Physiol. 119: 961-978.

Rogalski M and Carrer H (2011). Engineering plastid fatty acid biosynthesis to improve food quality and biofuel production in higher plants. Plant Biotechnol. J. 9: 554-564.

Sasaki Y and Nagano Y (2004). Plant acetyl-CoA carboxylase: structure, biosynthesis, regulation, and gene manipulation for plant breeding. Biosci. Biotechnol. Biochem. 68: 1175-1184.

Tan XF, Jiang Y, Wang BM and Zhang LN (2010). Cloning and sequence analysis of BC gene from Camellia oleifera. J. 
Central South Univ. Fores. Technol. 30: 1-9.

Thelen JJ, Mekhedov S and Ohlrogge JB (2000). Biotin carboxyl carrier protein isoforms in Brassicaceae oilseeds. Biochem. Soc. Trans. 28: 595-598.

Thelen JJ, Mekhedov S and Ohlrogge JB (2001). Brassicaceae express multiple isoforms of biotin carboxyl carrier protein in a tissue-specific manner. Plant Physiol. 125: 2016-2028.

Wang XN, Chen YZ, Wu LQ, Liu RK, et al. (2008). Oil content and fatty acid composition of Camellia oleifera seed. $J$. Central South Univ. Fores. Technol. 28: 11-17.

Zhang J, Qi C, Pu H, Chen S, et al. (2007). Inheritance and QTL identification of oil content in rapeseed Brassica napus L. Acta Agron. Sin. 33: 1495-1501.

Zhou CF (2013). Changes of ingredients and genes expression of lipid metabolism associated with seeds development of Camellia oleifera Abel. Doctoral thesis, Chinese Academy of Forestry. 